\title{
Evolución de los modelos jurídicos aplicados en la formalización de la propiedad rural, en particular en el proceso de titulación de baldíos rurales en Colombia
}

\author{
Evaluation of the legal models applied in the formalization \\ of rural property, in particular in the process of titling rural \\ vacant land in Colombia
}

\author{
Lizandro Alfonso Cabrera Suárez $z^{1} \bowtie$
}

${ }^{1}$ Magíster en Derecho, Universidad Sergio Arboleda, Bogotá. Abogado, Universidad Santiago de Cali.
Investigador junior, Colciencias. Par Académico del men. Profesor postgrados Uniamazonia.
Director de formación Incolballet Cali.

Correo electrónico: lizandrocabrera@hotmail.com

Recibido: 11 de julio del 2018 Aprobado: 20 de octubre del 2018 Disponible en línea: 5 de enero del 2019

Cómo citar este artículo: Lizandro Alfonso Cabrera-Suárez. Evolución de los modelos jurídicos aplicados en la formalización de la propiedad rural, particularmente en el proceso de titulación de baldíos rurales en Colombia. DIxı 28. Julio 2018. doi: https://doi.org/10.16925/2357-5891.2018.02.02

\section{Resumen}

Objetivo: la presente investigativa realiza un análisis exhaustivo sobre la evolución normativa y jurisprudencial de la titulación de bienes baldíos de carácter rural en Colombia.

Metodología: para esto se han planteado tres objetivos. El primero tiende a identificar y analizar los antecedentes de carácter normativo tanto históricos como vigentes que han regulado el tema de la titulación de bienes baldíos de carácter rural en Colombia; el segundo, identificar y analizar la línea jurisprudencial de la Corte Constitucional en el tema de la titulación de bienes baldíos de carácter rural a partir de la revisión de sentencias de tutela y de constitucionalidad expedidos por dicha corporación; el tercero, analizar lo establecido en la Ley 160 de 1994 y lo consagrado en el Acuerdo Final para la Terminación del Conflicto, en relación con la titulación de baldíos en Colombia. A fin de responder a cada uno se ha planteado un diseño de investigación descriptiva dentro del enfoque de investigación jurídica.

Resultados y conclusiones: aunque en materia de reforma agraria en Colombia se ha intentado pasar de un concepto simple basado en la propiedad de la tierra a uno integral que aborde de manera totalitaria la problemática rural, en la práctica no se ha logrado desarrollar, a pesar de los esfuerzos normativos en la materia.

Palabras clave: normatividad, jurisprudencia, titulación de bienes baldíos. 


\title{
Evaluation of the legal models applied in the formalization of rural property, in particular in the process of titling rural vacant land in Colombia
}

\begin{abstract}
Objective: This research makes an exhaustive analysis on the normative and jurisprudential evolution of the titling of rural land assets in Colombia.

Methodology: Three objectives are proposed: the first is to identify and analyze historical and current normative antecedents that have regulated the theme of the titling of rural land assets in Colombia; the second, to identify and analyze the jurisprudential line of the Constitutional Court in the subject of the titling of vacant land assets of a rural character, based on the review of tutelage and constitutionality sentences issued by that corporation; the third, to analyze what was established in Law 160 of 1994 and the one consecrated in the Final Agreement for the End of the Conflict, regarding the titling of vacant lands of Colombia. In order to respond to each objective, a descriptive research design is proposed within the legal research approach.

Results and conclusions: although in the area of agrarian reform in Colombia, it has been tried to move from a simple concept, based on land ownership, to an integral one that tackles rural issues in a totalitarian way, in practice, it has not yet been possible to develop, despite the normative efforts in the matter.
\end{abstract}

Keywords: normativity, jurisprudence, titling of vacant land assets.

\section{Avaliação dos modelos jurídicos aplicados na formalização da propriedade rural, em particular no processo de titulação de terrenos baldios rurais na Colômbia}

\section{Resumo}

Objetivo: esta pesquisa realiza uma análise exaustiva sobre a evolução normativa e jurisprudencial da titulação de bens de terrenos baldios de caráter rural na Colômbia.

Metodologia: para isso, são propostos três objetivos: o primeiro é identificar e analisar os antecedentes de caráter normativo tanto históricos quanto vigentes que têm regulamentado o tema da titulação de bens de terrenos baldios de caráter rural na Colômbia; o segundo, identificar e analisar a linha jurisprudencial da Corte Constitucional no tema da titulação de bens de terrenos baldios de caráter rural a partir da revisão de sentenças de tutela e de constitucionalidade expedidos por essa corporação; 0 terceiro, analisar o estabelecido na Lei 160 de 1994 e o consagrado no Acordo Final para o Término do Conflito, no que se refere à titulação de terrenos baldios da Colômbia. A fim de responder a cada objetivo, propõe-se um desenho de pesquisa descritiva dentro da abordagem de pesquisa jurídica.

Resultados e conclusões: embora, em matéria de reforma agrária na Colômbia, tenha se tentado passar de um conceito simples, baseado na propriedade da terra, a um integral, que aborde de maneira totalitária a problemática rural, na prática, ainda não foi possível desenvolver, apesar dos esforços normativos na matéria.

Palavras-chave: normatividade, jurisprudência, titulação de bens de terrenos baldios. 


\section{INTRODUCCIÓN}

En Colombia, el acceso a la tierra y la formalización de la propiedad rural ha sido un factor fundamental de la problemática rural identificado y aceptado por diferentes actores, a tal grado que hace parte del punto uno ("Reforma Rural integral") del "Acuerdo Final para la Terminación del Conflicto y la Construcción de una Paz Estable y Duradera”. Durante varias décadas nuestro país ha realizado diversos intentos por atender esta problemática, para lo cual ha generado un contexto normativo que intentó resolver de fondo la enmarañada situación de la propiedad rural. La normatividad colombiana ha previsto diversos mecanismos para formalizar la propiedad rural, entre los cuales se destaca el proceso de titulación de baldíos. De una manera apresurada se ha identificado que este procedimiento de titulación de baldíos a personas naturales -familias campesinas ocupantes y población desplazada - se encuentra regulado por la Ley 160 de 1994 y sus decretos reglamentarios 2664 de 1994 y 0982 de 1996, entre otras normas relevantes. En este contexto, se pretende establecer cuál ha sido la evolución de los modelos jurídicos aplicados en la formalización de la propiedad rural, en particular en el proceso de titulación de baldíos rurales en Colombia.

\section{MARCOS REFERENCIALES}

\section{A. Estado del arte}

La literatura académica ha señalado la importancia de la tierra, su distribución, su uso, sus derechos de propiedad y sus vínculos locales como determinante para entender la estructura del poder económico, al igual que los conflictos del sector rural.

En relación con el tema específico de la adjudicación de baldíos, se destaca el aporte de autores como Parsons, ${ }^{1}$ LeGrand, ${ }^{2}$ Balcázar et al., ${ }^{3}$ Machado $^{4}$

\footnotetext{
1 Cf. Parsons. La COlonización antioqueña EN EL OCCIDente De Colombia. Banco de la República. (1961).

$2 C f$. Catherine LeGrand. Colonización y protesta campesina en Colombia 1850-1950. Universidad Nacional de Colombia. (1988).

3 Cf. Álvaro Balcázar, Nelson López, Martha Lucía Orozco y Margarita Vega. Colombia: AlCANCeS y LeCCIONeS DE SU EXPERIENCIA EN REFORMa Agraria. Santiago de Chile: Naciones Unidas-Red de Desarrollo Agropecuario, Unidad de Desarrollo Agrícola, División de Desarrollo Productivo y Empresarial. (2001)

4 Cf. Absalón Machado. Ensayos para la historia de la política de tierras en Colombia. Universidad Nacional de Colombia. (2009).
}

y Palacios ${ }^{5}$ y Montalvo , ${ }^{6}$ quienes han profundizado en los procesos de adjudicación de baldíos en Colombia.

En primer lugar, Machado ${ }^{7}$ realiza un análisis de largo plazo, desde la Colonia hasta la década de los sesenta del siglo $\mathrm{xx}$, a fin de mostrar las políticas de distribución de la propiedad y la dificultad para modificar la concentración de la propiedad rural. El análisis permite entender las tensiones sociales que llevan a las políticas y leyes de tierras, así como los obstáculos institucionales y políticos para lograr efectos importantes en cuanto a la adjudicación de tierras. La revisión de la amplia legislación de tierras baldías permite concluir que la normatividad es amplia y desarticulada, aunque esto no es una razón suficiente que permita explicar la inoperancia de las políticas y la dificultad del Estado para dar solución a los problemas históricos de acceso a la tierra en Colombia.

Por su parte, Montalvo ${ }^{8}$ lleva a cabo un recuento de toda la legislación de adjudicación de tierras realengas y baldías desde la Colonia hasta principios del siglo xx. En este trabajo se observa el esfuerzo realizado durante la época republicana para adjudicar tierras del Estado como mecanismo de pago de deuda interna e incentivo para la inmigración internacional. Luego se concentra en los cambios que se dan en 1912 con la expedición del Código Fiscal y las posibles ambigüedades legales referentes a los mecanismos para acceder a la propiedad de la tierra, la posibilidad de transarla y la entrada de extranjeros al país con el fin de explotar en tierras baldías. En esta misma dirección se encuentran los trabajos de recopilación de todas las leyes de baldíos en Colombia como, por ejemplo, los de Amézquita, ${ }^{9}$ el Incora, ${ }^{10}$ Botero $^{11}$ y Castañeda, ${ }^{12}$ en los que se realiza un recuento

\footnotetext{
5 Cf. Marcos Palacios. ¿De Quién es la tierra? Propiedad, POLITIZACIÓN Y PROTESTA CAMPESINA EN LA DÉCADA DE 1930 Fondo de Cultura Económica, Universidad de los Andes. (2011).

Cf. Montalvo. (1914).

Cf. Machado, supra, nota 4.

Cf. Montalvo, supra, nota 6.

Cf. Josefina Amezquita de Almeida. RÉGIMEN LEGAL DE BALDíos EN Colombia. Editorial Temis. (1961).

10 Cf. Incora COMPILACIÓN DE NORMAS SOBRE ADJUdICACIONES BALDÍOS, RESERVAS INDÍGENAS, PARCELACIONES. Publicaciones del Incora. (1970).

$11 C f$. Juan José Botero. AdJUdiCACión, EXPLOTACión Y COMERCIALIZACIÓN DE BALDÍOS Y BOSQUES NACIONALES. EVOLUCIÓN HistóriCo LEgislativa, 1830-1930. Banco de la República. (1994). 12 Cf. Héctor Castañeda. Los baldíos en Colombia. Grupo Editorial Leyer. (1998).
} 
descriptivo de los cambios legales referentes a tierras baldías, los bosques y las reservas naturales.

Por otra parte, el trabajo de Parsons ${ }^{13}$ se concentra en explicar el modelo de colonización antioqueña en el occidente del departamento desde mediados del siglo xIx hasta principios del xx. Bajo la idea de modelo de colonización que llevó a la conformación de una sociedad democrática de pequeños y medianos propietarios con acceso libre a tierra de entre 60 y 150 fanegadas por familia. Este análisis ha sido retomado y ampliado por López Toro, ${ }^{14}$ quien además de caracterizar el acceso a la tierra en Antioquia plantea la importancia del contexto particular que experimentó esta región, lo que aportó al crecimiento más que una característica específica de su cultura y su gente.

Estos trabajos se complementan con otros que han realizado una revisión y un análisis particular de la reforma agraria a la luz de las distintas leyes, y en los que se destaca el énfasis en la Ley 200 de 1936, la Ley 135 de 1961 y algunos trabajos que incorporan en su análisis la Ley 160 de 1994.

Además, se encuentra el trabajo emblemático de LeGrand, ${ }^{15}$ el cual hace una búsqueda y una revisión de documentos históricos con el fin de presentar un recuento de la colonización campesina, la expansión de la frontera agrícola y las luchas que surgieron alrededor de la ocupación de la tierra en Colombia. Este autor afirma que la economía exportadora propició la apropiación en gran escala de la tierra y del trabajo por parte de la élite empresarial a fines del siglo XIX y comienzos del siglo xx, y que la apertura de mercados de ultramar hacia 1850 ofreció nuevas oportunidades económicas para campesinos y terratenientes. Muchas familias sin títulos de propiedad limpiaban y sembraban la tierra; luego eran desalojadas por empresarios y grandes terratenientes que habían solicitado títulos de propiedad cuando los precios de la tierra habían aumentado. De hecho, la formación de grandes propiedades mediante la desposesión de colonos fue una tendencia dominante entre 1870 y 1920, y la creciente concentración de la propiedad dio origen a muchas luchas por la tierra.

Por su parte, Palacios ${ }^{16}$ se hace una pregunta compleja, aunque simple en su formulación: ¿De quién es la tierra? Interrogante que le permite abordar

13 Cf. Parsons, supra, nota 1.

14 Cf. Álvaro López Toro. Migración y cambio social en Antioquia durante el siglo XIX. Demografía y ECONOmía 2(3). 1968. Págs. 351-403.

15 Cf. LeGrand, supra, nota 2.

16 Cf. Palacios, supra, nota 5. la importancia de la tierra desde tres puntos de vista: el político, el social y el económico. Estos puntos han llevado a conflictos tanto por el acceso como por la propiedad y el uso de la tierra, situación que se observa en la década de los treinta del siglo xx, en la cual se dio la presión por la tierra por las rentas asociadas al uso en actividades de exportación, la presión de los terratenientes por demostrar su posesión y el conflicto con los colonos que ven posibilidades de uso y de acceso a través de las nuevas leyes.

En cuanto a los alcances y el desempeño de la reforma agraria posterior a la Ley 135 de 1961 Tobón ${ }^{17}$ subraya que los efectos en la distribución no fueron los señalados en la ley (es decir, el carácter social), sino que favoreció intereses capitalistas y no logró una modificación de la estructura de tenencia del país. Al respecto se menciona que la gran propiedad apenas fue afectada, pues solo se expropiaron 23 predios mayores a 960 hectáreas que no alcanzan a ser 60000 hectáreas de tierra. Además, el 52\% del área comprada para las parcelaciones necesitó de obras de adecuación, lo cual indica que eran tierras de mala calidad que debían acondicionarlas antes de entregarlas. Esto provocó un aumento en los precios que los campesinos tenían que pagar, mientras que los terratenientes hacían dinero con la venta de malas tierras. En las actividades de adecuación se gastaron $2 / 3$ partes del presupuesto invertido en compras, mientras que las tierras que se podían entregar de forma inmediata requirieron $1 / 3$ del presupuesto.

Por su parte, Balcázar et al. ${ }^{18}$ parten de una afirmación contundente según la cual el Estado colombiano ha gastado sumas significativas para intentar una reforma redistributiva de la tierra, pero los resultados son menos que marginales. Evalúan el impacto social y en actividades agropecuarias a partir de una encuesta aplicada en tres regiones en las que se han realizado acciones de reforma agraria (Tolima, Huila y Sucre), escogiendo al azar fincas en cada región para aplicar las encuestas a hogares que hayan sido beneficiarios de la reforma agraria desde 1962. Según los resultados, los hogares beneficiados por la reforma agraria utilizan un mayor porcentaje de su tierra para actividades agrícolas en comparación con hogares en similares circunstancias sin beneficios. El efecto es aún mayor entre quienes recibieron tierra a través del

\footnotetext{
17 Tobón. (1972).

$18 C f$. Álvaro Balcázar, Nelson López, Martha Lucía Orozco y Margarita Vega, supra, nota 3.
} 
mercado de tierras, es decir, quienes fueron beneficiados después de la Ley 160 de 1994.

En cuanto al alcance de la Ley 160 de 1994, el trabajo del Banco Mundial ${ }^{19}$ examina el funcionamiento del mercado de tierras y de la transferencia de tierras a menores productores por medio de la compra-venta de tierras y de los mercados de arrendamientos. A partir de una estimación de un modelo probit, en el estudio se encuentra que existe una probabilidad mayor de acceder a tierras mediante los mercados de arrendamientos, es decir, el programa de reforma agraria del Gobierno fue menos efectivo que el mercado para transferir tierra a pequeños productores.

Desde una perspectiva más amplia de la reforma agraria, se encuentran los trabajos de Gutiérrez, ${ }^{20}$ Machado, ${ }^{21}$ Rosas, ${ }^{22}$ Berry, ${ }^{23}$ Kalmanovitz y López, ${ }^{24}$ entre otros, los cuales han abordado el tema de la asignación de tierra asociado a los conflictos agrarios que ha experimentado el país y las políticas de tierras o de "reforma agraria". No son trabajos explícitos sobre la adjudicación de baldíos en Colombia, pero sí han planteado algunas hipótesis sobre el alcance de la política de baldíos en Colombia. Entre otras, Kalmanovitz y López ${ }^{25}$ señalan que en las primeras décadas del siglo xx existe una tendencia a la concentración de los baldíos adjudicados y que los derechos de propiedad de la adjudicación de tierras baldías han sido difíciles de proteger, tanto por los terratenientes como por el Estado, en razón a la incapacidad de este de proteger y hacer valer estos derechos.

Berry ${ }^{26}$ afirma que el patrón de control y uso de la tierra en Colombia se caracteriza por la ambigüedad de quién controla la tierra; la importancia relativa del Estado como gran poseedor de tierra baldía; la incoherencia de la política del Estado que cambia dependiendo del partido en el poder y el estrecho

19 Cf. Banco Mundial. Colombia: unA Política de tierras en TRANSICIÓN. Documento CEDE, 2004-29, Facultad de Economía, Universidad de los Andes. (2004).

20 Cf. Francisco Gutiérrez Sanín. Desigualdad extrema: una PREOCUPACIÓN POLÍTICA. LAS POLÍTICAS RURALES EN COLOMBIA EN EL PERIODO 2002 -2009. (2012).

21 Cf. Absalón Machado. Reforma agraria. Una ilusión que terminó en fracaso. Revista Credencial Historia 119. 1999.

22 Cf. Gabriel Rosas. (2005). Reforma agraria, no más dilaciones. Economía Colombiana 309. Págs. 33-44.

23 Cf. Albert Berry. (2002). ¿Colombia encontró por fin una reforma agraria que funcione? Revista DE Economía Institucional 4(6). Pág. 24-70.

24 Cf. Salomón Kalmanovitz y Enrique López. LA AGricultura Colombiana en el siglo xx. Banco de la República. (2006).

25 Id.

$26 C f$. Berry, supra, nota 23. vínculo entre tierra y otros asuntos rurales como, por ejemplo, el acceso a la fuerza de trabajo. Es decir, en términos de la política de baldíos, el país no ha contado con el entorno apropiado, en especial desde el punto de vista de voluntad política que permita resolver las dificultades que una buena política de reforma agraria intenta.

Estudios más recientes vinculan la cuestión de la tierra con el conflicto que ha experimentado el país y retoman el alcance de la política de acceso a la tierra con el fin de mostrar que aún subsiste la tensión social asociada al acceso a la tierra. En particular el Programa de las Naciones Unidas para el DesarrolloPNUD $^{27}$ señala que las reformas agrarias en Colombia han fracasado como mecanismos para disminuir la pobreza y reducir la inequidad. A esto se incorporaron componentes de una nueva violencia que involucra a las guerrillas, el narcotráfico y los paramilitares, los cuales dificultaron y dejaron sin efectos las leyes de redistribución que se impusieron en el país a partir de la política agraria de 1994.

Frente a esta situación otros autores han tratado de estudiar algunas alternativas de políticas públicas a fin de aumentar el acceso a la tierra y los ingresos de la población rural, a partir de la situación actual de la concentración de la propiedad en las zonas rurales. Por ejemplo, Gáfaro, Ibáñez y Zarruk ${ }^{28}$ presentan el problema de la distribución de la tierra en Colombia, y encuentran que, en lugar de disminuir, la concentración de la tierra aumentó entre el 2000 y el 2009, y cómo la informalidad de la tierra es frecuente para los pequeños productores, sobre todo para la población más pobre. Los autores mencionan que esto coincide con las regiones recientemente colonizadas y con la baja presencia institucional. Además, reconocen que esto se encuentra relacionado con el fracaso de las tres reformas agrarias del siglo $\mathrm{xx}$, debido a su mal diseño, a la creación de incentivos perversos, la debilidad institucional y la falta de programas complementarios, todo lo cual llevó a que se diera una distribución muy marginal de tierras de buena calidad, a que se asignaran baldíos en zonas aisladas y a que se incrementara la informalidad de los derechos

27 Cf. Programa de las Naciones Unidas para el DesarrolloPNUd. Colombia RuRAL: RAZONES PARA LA ESPERANZA. INFORME Nacional de Desarrollo Humano. Programa de las Naciones Unidas para el Desarrollo. (2011).

28 E.g. Margarita Gáfaro, Ana María Ibáñez y David Zarruk. EQUIDAD Y EFICIENCIA RURAL EN COLOMBIA: UNA DISCUSIÓN DE POLÍTICAS PARA EL ACCESO A LA TIERRA. (2012). Documentos CEDE 010318. Universidad de los Andes-CEDE. 
de propiedad, mientras no se alcanzaban los objetivos de aumentar la producción agropecuaria, ni la reducción de la pobreza rural.

En conclusión, se observa una literatura que ha hecho el recuento de la reforma agraria, sus tensiones políticas, el vínculo con el conflicto armado y la intensión de mejorar la condición de vida rural mediante la entrega de baldíos a campesinos. Según los estudios, los resultados de los distintos intentos no parecen ser los esperados. Como señala Machado, los objetivos de la reforma agraria eran claros en términos teóricos, pero "su aplicación en un sistema institucional descoordinado, sin estrategias definidas a largo plazo y sin liderazgo, echaron por la borda los conceptos y los paradigmas". ${ }^{29}$

Por su parte, Rosas afirma que se han ensayado prácticamente todos los modelos de reforma agraria en Colombia, "sólo que no se ha contado con la organización institucional adecuada ni se ha puesto la voluntad política indispensable para hacerlas efectivas". ${ }^{30}$

Es decir, durante más de 100 años el país ha planteado alternativas para una configuración institucional y estructural rural más productiva y equitativa, pero no lo ha logrado. Varias razones se pueden encontrar en este penoso resultado de las políticas de tierra. Tal como lo menciona Machado, parece un problema de disonancia entre las políticas, el arreglo institucional vigente y la perspectiva de país que se tenía en mente. El corto plazo alentó la formulación de políticas públicas de tierra bajo un esquema institucional excluyente y cargado de tensiones y poderes políticos. Bajo esta situación, el éxito de la reforma agraria hubiese sido una coincidencia prácticamente imposible. El país ha alcanzado lo que ha podido, dado el panorama institucional, legal y la voluntad política a lo largo del siglo xx.

Si bien la preocupación por la reforma agraria en Colombia ha sido amplia y se ha analizado desde distintas perspectivas, subsisten vacíos muy genéricos. En tal sentido, en una primera medida este documento observa la construcción de una normatividad compleja, muchas veces no acorde con la realidad rural del país, ni con interés político para su desarrollo.

29 Véase Absalón Machado y Ruth Suárez. Coord. El Mercado De tierras en Colombia: ¿una alternativa viable? Centro de Estudios Ganaderos y Agrícolas (CEGA), Instituto Interamericano de Cooperación para la Agricultura (IICA). (1999). Pág. 1.

30 Rosas, supra, nota 22, pág. 34.

\section{B. Marco teórico}

El desarrollo de la presente propuesta se enmarca en un paradigma de investigación jurídico por cuanto pretende, a partir de un estudio normativo y comparativo de la legislación colombiana en materia de titulación de baldíos, resolver el problema.

\section{Marco jurídico}

La constitución Política de Colombia de 1991 señala como un deber del Estado promover el acceso progresivo a la propiedad de la tierra de los trabajadores agrarios, de forma individual o asociativa. Establece en el artículo 150 la función del Congreso de dictar las normas sobre apropiación o adjudicación y recuperación de tierras baldías.

Por su parte, en el Decreto Ley 902 de 2017 se adoptan medidas para facilitar la implementación de la Reforma Rural Integral contemplada en el Acuerdo Final en materia de tierras, específicamente el procedimiento para el acceso y formalización y el Fondo de Tierras

Ahora bien, en el Acto Legislativo 001 de 2016 se establecen instrumentos jurídicos con el fin de facilitar y asegurar la implementación y el desarrollo normativo del acuerdo final para la terminación del conflicto y la construcción de una paz estable y duradera.

En el Acuerdo final para la terminación del conflicto y la construcción de una paz estable y duradera se desarrollan, en el punto 1.1.1, el Fondo de Tierras para la Reforma Rural Integral, y en el punto 1.1.5, la formalización masiva de la pequeña y mediana propiedad rural.

En la Ley 1753 de 2015 se expide el Plan Nacional de Desarrollo 2014-2018 “Todos por un nuevo país". En los artículos 102 y 103 se establece el "Marco especial sobre administración de tierras de la Nación y la Formalización de la propiedad rural".

En el Acuerdo 037 de 2005 del extinto Incoder se dicta el reglamento especial de adjudicación y aprovechamiento de los predios rurales ingresados al patrimonio de la Nación con carácter de baldíos reservados, en virtud de la declaratoria de extinción del derecho de dominio privado.

Por medio de la Ley 160 de 1994 se crea el Sistema Nacional de Reforma Agraria y Desarrollo Rural Campesino. Allí se establece un subsidio para la adquisición de tierras, se reforma el Instituto 
Colombiano de la Reforma Agraria y se dictan otras disposiciones.

La Resolución N. 041 de 1996 del extinto Incora determina las extensiones de las unidades agrícolas familiares, por zonas relativamente homogéneas.

La Ley 4 de 1973 introduce modificaciones a las leyes 200 de 1936, 135 de 1961 y 1a de 1968, además, señala que no podrán hacerse adjudicaciones de baldíos sino a favor de personas naturales y por extensiones no mayores de 450 hectáreas. Con una excepción de 3000 ha por resolución.

Finalmente, la Ley 135 de 1961 sobre la reforma agraria integral se crea el Instituto Colombiano de Reforma Agraria

\section{ANTECEDENTES NORMATIVOS DEL PROCESO DE FORMALIZACIÓN DE LA PROPIEDAD RURAL EN COLOMBIA}

Las diversas civilizaciones de la historia han basado su estructura de poder económico en la tierra, su distribución y sus derechos de propiedad. Colombia, al igual que Latinoamérica no ha sido ajena a esta tendencia, muchas de las dinámicas sociales y políticas a lo largo del siglo xx obedecieron a un problema estructural de diferencias sobre la distribución de la tierra. Para este siglo varios países implementaron reformas con el objetivo de mitigar las diferencias distributivas, sin embargo, las estructuras de poder económico, político y armado evitaron en algunos casos cumplir los presupuestos necesarios para impulsar las economías agrarias, como sucedió en el caso de Colombia. ${ }^{31} \mathrm{Al}$ constituirse la titulación de baldíos como un mecanismo para acceder a la tierra en Colombia, ha existido una presión continua entre los diferentes actores (campesinos, terratenientes y empresarios), las cuales se evidencian aún en la actualidad.

\section{A. Los bienes baldíos en Colombia}

Los baldíos son bienes públicos de la Nación catalogados dentro de la categoría de bienes fiscales adjudicables, en razón a que la Nación los conserva para adjudicarlos a quienes reúnan la totalidad de

31 Véase Salomón Kalmanovitz y Enrique López, supra, nota 24. Pág. 23-31. las exigencias establecidas en la ley. ${ }^{32}$ Los baldíos son terrenos, predios, bienes inmuebles que al estar dentro de los límites fronterizos, son propiedad del Estado por carecer de otro dueño. De acuerdo con Martínez de Aparicio, ${ }^{33}$

Los baldíos pueden estar ubicados dentro de los perímetros considerados como rurales y en los establecidos como urbanos, dentro de la clasificación de los suelos. Este punto es de vital importancia, ya que dependiendo de su ubicación, serán clasificados en rurales o urbanos y les será aplicable un conjunto de normas diferentes de acuerdo con esa clasificación.

La titulación de baldíos hace parte de la política de formalización de la propiedad rural y se dirige a regular la ocupación y el aprovechamiento de las tierras baldías de la Nación, al darle preferencia en su adjudicación a los campesinos de escasos recursos. Su fin es satisfacer las necesidades del ocupante, permitir el acceso a la propiedad de la tierra a quienes carecen de ella y contribuir a mejorar las condiciones económicas y sociales de los adjudicatarios. ${ }^{34}$

La Ley 160 de $1994^{35}$ creó el Sistema Nacional de Reforma Agraria y Desarrollo Rural Campesino y señaló como único fin único de los baldíos el de ser adjudicados a los particulares que carecen de tierras, a fin de que estos los exploten económicamente. Los terrenos baldíos solo puede adquirirse mediante título traslaticio de dominio, otorgado por el Estado a través del Incora o la entidad pública delegada. Antes de la vigencia de esta Ley no existía claridad sobre el procedimiento de adjudicación, por tanto, esta estableció las limitaciones y prohibiciones que se debían tener en cuenta al momento de la adjudicación.

El Decreto 2363 de $2015^{36}$ le atribuye a la Agencia Nacional de Tierras (ANT) la administración de las tierras baldías de la Nación, adelantar los procesos

\footnotetext{
32 Cf. Corte Constitucional Colombiana. Sentencia C-595/95. (MP Carlos Gaviria Díaz: diciembre 7 de 1995).

33 Véase José M. Martínez Aparicio. Régimen de Baldíos. Ediciones 2000.

34 Cf. Ministerio de Agricultura y Desarrollo Rural. Cartilla DE POlítiCA AGROPECUARIA 2010-2014. Ministerio de Agricultura y Desarrollo Rural. (2012).

35 Cf. Ley 160 de 1994. Por la cual se crea el Sistema Nacional de Reforma Agraria y Desarrollo Rural Campesino, se establece un subsidio para la adquisición de tierras, se reforma el Instituto Colombiano de la Reforma Agraria. Agosto 3 de 1994. Do 41479.

36 Cf. Decreto 2363 de 2015. Por la cual se crea la Agencia Nacional de Tierras ANT, se fija su objetivo y estructura. Diciembre 7 de 2015.
} 
generales y especiales de titulación y transferencias a las que haya lugar, delimitar y constituir reservas sobre celebrar contratos para autorizar su aprovechamiento y regular su ocupación sin perjuicio de lo establecido en los parágrafos 5 y 6 del artículo 85 de la Ley 160 de 1994. Con el Decreto Ley 902 de $2017,{ }^{37}$ por el cual se adoptan medidas para facilitar la implementación de la "Reforma Rural Integral" contemplada en el Acuerdo Final en materia de tierras, específicamente en el procedimiento para el acceso y formalización y el fondo de tierras, se realizan ajustes al procedimiento establecido en la Ley 160 de 1994 y sus decretos reglamentarios en materia de titulación de baldíos.

\section{B. El siglo XIX y la distribución de baldíos}

LeGrand ${ }^{38}$ señala que, durante un periodo largo del siglo XIX, la política sobre los baldíos tuvo dos tendencias: estuvo destinada a fomentar el crecimiento rural y la colonización, y fue una fuente de ingresos para el Estado, el cual los vendía al mejor postor para cubrir déficits fiscales generados por los conflictos regionales o los entregaba en concesión a fin de pagar deudas.

La Ley 61 de $1874^{39}$ intentó determinar el uso de la tierra en cultivos como el criterio de asignación de los baldíos cualquiera fuera su extensión, al entregar otro terreno adyacente de igual tamaño si se vivía y trabajaba en ella. Sin embargo, también animó a personas ricas a tener todas las tierras que pudieran pagar. Los conflictos continuaron de tal manera que la Ley 48 de $1882^{40}$ reconoció a los colonos como independientes y definió entre sus objetivos que "los cultivadores de las tierras baldías establecidos en ellas con caza y labranza, serán considerados como poseedores de buena fe y no podrán ser privados de la posesión sino por sentencia dictada en juicio civil ordinario".

Salgado y Prada $^{41}$ expresan que, dada la importancia que se le reconocía al campesinado para aportar al desarrollo económico y controlar a los terratenientes, la Ley 48 de 1882 introdujo regulaciones

\footnotetext{
37 Véase http://www.agenciadetierras.gov.co/normativa/ decretos/.

38 Cf. LeGrand, supra, nota 2.

39 Véase http://www.suin-juriscol.gov.co/viewDocument.asp? id $=1614234$

40 Tomado de: http://www.banrepcultural.org/sites/default/files/ $88066 /$ brblaa 877

41 Véase Carlos Salgado y Esmeralda Prada. CAMPEsinado y PROTESTA SOCIAL EN COLOMBIA, 1980-1995. Cinep. (2000).
}

que permitieron reducir de manera progresiva la cantidad de tierra a ser asignada, que pasó de 5000 hectáreas en 1882 a 2500 en 1912, determinándose que tierras improductivas durante 10 años revertían al Estado. Sin embargo, el periodo entre 1870 y 1920 fue de intensas confrontaciones por la usurpación de los terratenientes y el acaparamiento de empresas.

\section{Antecedentes de la discusión agraria en Colombia desde la primera mitad del siglo XX}

En la primera mitad del siglo $\mathrm{xx}$ se promovieron intentos de reforma agraria, particularmente impulsadas en el periodo 1920-1930, las cuales en caso de haber tenido éxito habrían permitido un mejor desarrollo económico e impactado de forma positiva el campo colombiano. ${ }^{42}$ Soportados en el Partido Liberal, los colonos y campesinos se mostraron como una clase fuerte, inconforme con la realidad económica y social del campo colombiano, lo que generó un ambiente de inseguridad entre la élite política del país. Si bien el Gobierno tenía como eje de su política pública la industrialización de la economía, conocían la importancia de no descuidar la política agraria, ya que tenían presente la inconformidad social del sector rural por la inequitativa distribución de las tierras.

En el gobierno de Alfonso López Pumarejo se expidió la Ley 200 de 1936, la cual, de acuerdo con algunos autores, fue positiva para los pequeños campesinos. Sin embargo, también sirvió como instrumento legal por medio del cual muchos terratenientes pudieron efectuar la titulación de terrenos baldíos, ${ }^{43} \mathrm{y}$ para algunos autores empeoró la calidad de vida de los campesinos que aspiraban a acceder a la tierra. A partir de su expedición se generó un fuerte movimiento de privatización de tierras que conllevó a agudizar la violencia campesina en las siguientes décadas e incrementó la concentración de la tierra, contrario a casos exitosos de reforma agraria de otros países como, por ejemplo, los de países hoy industrializados de Asia Oriental como Taiwán, Corea del Sur, Singapur y Hong-Kong, los cuales tuvieron un diferencial en su

42 Cf. Albert Berry. ¿Colombia encontró por fin una reforma agraria que funcione? RevisTA DE ECONOMÍA INSTITUCIONAL 4(6). 2008. Pág. 19-23.

$43 C f$. Ángela Barriga. ¿ACUMUlación IRREgular DE TIERRAS ADJUDICADAS COMO BALDíos? DUdAS ANTE LA EXPEDICIÓN DE LA LEY ZidRES Y SU POSIBLE DISONANCIA CON LO ACORDADO EN LA HABANA. (2017). 
política, en cuento eliminaron la posibilidad de tener haciendas de grandes extensiones de tierra sin que estas fueran productivas. ${ }^{44}$

En la década de 1930, la ciencia y la tecnología se ubicaron como elementos claves en el desarrollo económico del país, sin embargo, las diferencias y el poder político existente resquebrajó todas las posibilidades de avance, de modo que se dejó de lado la realidad política y social del país, sumida en un conflicto que dio pie al surgimiento de grupos armados en la segunda mitad del siglo $\mathrm{xx}^{45}$

\section{Ley 200 de 1936}

La Ley 200 de 1936, también denominada "Ley de tierras", contribuyó a implantar estructuras de tenencia de tierra para hacendados, así como le brindó una nueva legalidad a la gran propiedad que se cuestionaba entonces de manera organizada por el campesinado. Además de responder a las expectativas generadas frente al desarrollo de la producción agropecuaria y sus efectos en el desarrollo económico general cumplió, fundamentalmente, un papel político e ideológico. ${ }^{46}$ Con esta ley se pretendía dar un impulso sustancial a la utilización económica del suelo, clarificar los derechos de propiedad y posesión sobre baldíos, así como encuadrar los conflictos agrarios a un nuevo orden jurídico a través de la jurisdicción del Estado. De esta manera, la ley de tierras fue un intento por neutralizar las protestas rurales que se iniciaron en la década de los veinte, en particular el mencionado episodio funesto de la masacre de las bananeras en 1928, en la cual murieron centenares de trabajadores que exigían mejores condiciones laborales. ${ }^{47}$

Vanín Tello indica que la Ley 200 de 1936 constituyó el punto de partida hacia la formación de un derecho agrario en Colombia, creó nuevas instituciones jurídicas y transformó otras del derecho civil. ${ }^{48}$

44 Cf. Cristóbal Kay. Reforma agraria, industrialización y desarrollo: ¿Por qué Asia Oriental superó a América Latina? Debate Agrario 34. Págs. 45-94. 2002.

45 Cf. Machado, supra, nota 4.

46 Cf. Elsy Marulanda A. ApliCaCión y efeCtos De LA LEY 200 DE 1936 EN LA REgión DE SumAPAz. Universidad Nacional de Colombia (Sede Bogotá). Facultad de Ciencias Humanas. Departamento de Historia.

47 Cf. Gonzalo Sánchez y Ricardo Peñaranda. Pasado y PRESente de la violencia en Colombia. Cerec. (1986).

48 Cf. Joaquín Vanín Tello. Derecho Agrario Teoría General. Tomos 1 y 11. Editorial Universidad Externado de Colombia. (1986)

\section{E. La reforma agraria}

García Noratto ${ }^{49}$ manifiesta que, desde 1960, Colombia ha intentado desarrollar una reformar agraria sin alcanzar los resultados esperados. Entre estos, se encuentran sin solucionar los problemas derivados de la tenencia de la tierra. En este sentido, en un rápido recorrido normativo manifiesta que, si bien con normas como la Ley 135 de 1961 y la Ley 1 de 1968, de carácter distribucionista y marginal, solo se logró una reparación superficial de la estructura agraria; posteriormente, la Ley 4 de 1973 retrasó los procesos, los cuales posteriormente se agilizaron con la Ley 35 de 1982 que buscó agilizar el procedimiento para la entrega de tierra en áreas de conflicto a través del Plan Nacional de Rehabilitación. Con la Ley 30 de 1988 se introdujeron cambios importantes en el proceso de reforma agraria, en busca de remover los obstáculos legales y de procedimiento que hicieron impracticables las leyes anteriores.

La Ley 160 de 1994 podría comprenderse como la adecuación de la intervención del Estado para regular la estructura de la propiedad en un esquema de economía más abierta, al sustituir la intervención directa del Estado por la evolución del mercado asistido de tierras y crear un mecanismo a los agentes privados para que participen en él. Sin embargo, evidentemente los resultados no se dieron. En los últimos 50 años no se ha logrado una evolución significativa de la estructura de la propiedad y el acceso a tierras ha sido limitado, ya que ha dependido de los recursos del Estado, lo que ha conllevado a bajo impacto. De forma paralela, en las últimas dos décadas problemáticas tales como el desplazamiento y el narcotráfico han generado una contrarreforma agraria.

Las causas que no han permitido la implementación de una reforma integral son variadas, pues desde la falta de capacidad política hasta una escogencia inadecuada de estrategias y medios para lograr los objetivos, los enfoques normativos han modificado su énfasis.

\section{F. Ley 135 de 1961}

La Ley 135 propuso, por primera vez, la organización institucional para manejar los temas de una reforma

\footnotetext{
49 Cf. Olga Marina García Norato. Tendencias historiográficas sobre el problema agrario en Colombia siglo XX. REVISTA DE INVESTIGACIONES UNAD.
} 
agraria. El Incora fue la entidad estatal creada para encargarse del proceso de redistribución, de modo que el Estado adquirió cerca de 1,4 millones de hectáreas a partir de la compra de terrenos, la expropiación y las tierras cedidas por el Fondo Nacional Agrario.

A su vez se titularon a particulares alrededor de 5 millones de hectáreas. El beneficio total fue tan solo para 102000 familias que recibieron terrenos, unas 430000 hectáreas que pudieron titular. ${ }^{50}$ A pesar de los anteriores resultados, no se lograron mayores soluciones en razón a que en el campo se venía intensificando un conflicto característico de la violencia partidista de mitad de siglo. La reforma en mención fue el resultado de un pacto entre el Partido Liberal y Conservador, en pleno surgimiento del Frente Nacional, y a la aplicación de la Alianza para el Progreso diseñada por los Estados Unidos, en la cual se consignaba como uno de sus fines limitar el alcance del movimiento campesino, el cual ya no se encontraba dentro de los lineamientos de los partidos parte del acuerdo del Frente Nacional. ${ }^{51}$

\section{G. Ley 1 de 1968}

Con el fin de superar las fallas institucionales presentes, se expidió bajo el Gobierno de Carlos Lleras Restrepo la Ley 1 de 1968 — por la cual se introducen modificaciones a la Ley 135 de 1961-, la cual instituyó un esquema organizacional más estructurado del sector encargado de ejecutar la política pública de tierras. El proceso contó con la participación de la Asociación Nacional de Usuarios Campesinos (ANUC), sin embargo, no desarrolla mayores aspectos relacionados con la titulación del baldíos, enfocándose en la estructura del Incora, el Consejo Social Agrario y las procuradurías agrarias.

Esta norma asignó la facultad a la Junta Directiva del Incora de establecer tarifas para el cobro de los servicios de topografía sobre superficies mayores a 50 hectáreas.

\section{H. Ley 4 de 1973}

Con la Ley 4 de 1973 se propusieron cambios orientados a mitigar los efectos de la Ley 1 de 1968; se establecieron nuevos criterios para la calificación de

50 Cf. Álvaro Balcázar, Nelson López, Martha Lucía Orozco y Margarita Vega, supra, nota 3. Pág. 41.

51 Cf. Machado, supra, nota 4. Págs. 29-41. predios como adecuadamente explotados, mediante mínimos de productividad; se redujeron los trámites de adquisición de tierras mediante negociaciones directas; y la adjudicación de tierras a los beneficiarios se agilizó, de manera que apareció la renta presuntiva agrícola como herramienta para ejercer presión a favor del uso productivo de la tierra y penalizar su apropiación improductiva. Esto último dio origen al Desarrollo Rural Integrado (DRI) como estrategia complementaria a los programas de reforma agraria, ${ }^{52}$ sin embargo, históricamente se señala que esta norma frenó los procesos de reforma agraria.

Con esta norma se incorpora la posibilidad de realizar adjudicaciones en favor de entidades de derecho público con destino a servicios públicos, bajo la condición de que si dentro del término que el Incora señala no se da cumplimiento al fin previsto, los predios adjudicados revierten al dominio de la Nación.

\section{Ley 35 de 1982}

Con la Ley 35 de 1982 se decreta una amnistía y se dictan normas tendientes al restablecimiento y la preservación de la paz. Esta norma buscó agilizar los trámites para entrega de tierras en zona de conflicto (Plan Nacional de Rehabilitación). ${ }^{53}$

\section{J. Ley 30 de 1988}

Con la expedición de la Ley 30, el Gobierno de Virgilio Barco generaba uno de los soportes para la negociación de la paz en el país, fundamentada en la reactivación de los intereses por una reforma agraria que solucionara la desigualdad en el campo a partir de la definición de la función social de la propiedad. Sin embargo, desde 1985 ya se establecían los lineamientos de la apertura económica del país, de modo que se limitaba la acción del Estado en el fomento agrario a partir de la eliminación de subsidios, algo que se vería más explícito en la apertura económica que entra en vigencia desde $1990 . .^{54}$

Con la Ley 30 de 1988 se pretendía vincular más al campesinado a la actividad productiva y a la inclusión social, para lo cual se le dio a la mujer como vínculo familiar la capacidad de adquirir terrenos, se

52 Cf. Absalón Machado y Ruth Suárez, supra, nota 29.

53 Cf. Bersarión Gómez Hernández. La tenencia de la tierra y la reforma agraria en Colombia. VERBA IURIs. Enero-junio 2011

54 Cf. Machado, supra, nota 4. Pág. 72. 
abrió paso a la agilización judicial para este tipo de procesos, se buscó el fortalecimiento institucional, se dieron mayores responsabilidades al Incora, se fortaleció la capacitación, se dieron facilidades para arrendar maquinaria, prioridad al Estado para la adquisición de predios y mayor capacidad operativa del Estado para administrar la política de tierras, entre otras medidas. ${ }^{55}$

\section{K. Ley 160 de 1994}

Con la Ley 160 de 1994 se realizaron cambios profundos en el concepto de reforma agraria tradicional, y se pasó a un mecanismo en el que la propiedad se adquiría a través de la compra directa por parte de los campesinos, en la cual el 70\% del costo provenía de los campesinos y el restante $30 \%$ podía provenir de una línea de crédito especial de los intermediarios financieros, con el requisito de presentar un proyecto productivo o de recursos propios. ${ }^{56}$

Esta norma señala en el capitulo XIII los lineamientos de la política de baldíos, de manera que estableció como sujetos beneficiarios a campesinos y a empresas especializadas reconocidas por el Ministerio de Agricultura.

\section{La Constitución de 1991}

Con la aparición de la Constitución Política de 1991 de nuevo se abordaron temáticas de equidad y participación en su contenido. La nueva Constitución otorga a la tierra un sentido más amplio, de modo que adquiere un sentido social y ecológico.

Sin embargo, los esfuerzos de los años siguientes no fueron los más convenientes para el campo colombiano. De acuerdo con Machado, ${ }^{57}$ lo que se presentó luego de 1991 fue un abandono institucional por parte del Estado al campesinado colombiano, argumentado en la falta de importancia estratégica para lo que como modelo económico se idealizaba para el país.

55 Cf. Angélica María Franco e Ignacio de los Ríos. Reforma agraria en Colombia: evolución histórica del concepto. Hacia un enfoque integral actual. CUADERNOS DE DESARROLLO RURAL 8(67). 2011. Págs. 109 y 110.

56 Cf. Darío Fajardo M. La tierra y el poder político; la reforma agraria y la reforma rural en Colombia. Boletín FAO. RoMA. 2002.

57 Cf. Machado, supra, nota 4.
En igual sentido, Fajardo ${ }^{58}$ señala cómo a pesar de las circunstancias de apertura económica, en el Gobierno de Cesar Gaviria se reestructuró el papel del Incora y se le otorga un papel más de dinamizador terciario del mercado de tierras, lo cual limitó las funciones asignadas en la administración de Lleras.

Señalan Vargas et al. ${ }^{59}$ que luego de 1990, no solo la apertura, sino también la agudización del conflicto armado y la violencia, acabaron con muchas de las posibilidades de generar una verdadera política de tierras que atacara el problema principal del campo colombiano: la notable concentración de la tierra.

Después de la Ley 160 de 1994, el siguiente paso normativo fue la liquidación del Incora en el 2003, en la primera administración de Álvaro Uribe Vélez, la cual dio paso al Instituto Colombiano de Desarrollo Rural (Incoder), como entidad adscrita al Ministerio de Agricultura y Desarrollo Rural, la cual luego mediante el Decreto 2365 de 2015 se liquida para dar paso a la actual Agencia Nacional de Tierras (ANT).

\section{Problemática del acceso A TIERRA Y LA TITULACIÓN DE BALDÍOS EN COLOMBIA}

A pesar de lo complejo que la problemática relacionada con el acceso, la formalización y la distribución de la tierra, es evidente que las principales dificultades son:

Tabla 1. Adjudicación de baldíos en Colombia

\begin{tabular}{|l|c|c|c|c|}
\hline \multirow{2}{*}{$\begin{array}{c}\text { Periodos/ } \\
\text { proceso }^{* *}\end{array}$} & \multicolumn{2}{|c|}{$\begin{array}{c}\text { Titulación de baldíos a } \\
\text { colonos }^{*}\end{array}$} & \multicolumn{2}{c|}{$\begin{array}{c}\text { Titulación de baldíos a } \\
\text { comunidades negras }\end{array}$} \\
\cline { 2 - 5 } & Familias & Has & Familias & Has \\
\hline $1962-1984$ & 291569 & 10006268 & & \\
\hline $1985-2000$ & 174666 & 174666 & 21945 & 21945 \\
\hline $2001-2018$ & 89285 & 2486004 & 44507 & 3002789 \\
\hline Total & 555520 & 20179387 & 66452 & 5298009 \\
\hline
\end{tabular}

Fuente: Incoder. ${ }^{\star}$ Para $1962-2000$ se habla de predios. ${ }^{*}$ Para 1962 2018 son datos de CGR.

$58 C f$. Darío Fajardo. Colombia: reforma agraria en la solución de conflictos armados. América Latina, Hoy 23. (1999). Págs. 45-59.

59 Cf. César Vargas, Gonzalo Téllez, Alexander Cubillos, Jaime Pulido, Paola Gómez y Lady Garzón. Análisis de los beneficiarios de la Política Pública de Reforma Agraria en el marco del desarrollo rural en Colombia (1994-2010). PAMPA 13. 2016. Págs. 31-53. 
- Sistema de información. No están claramente definidas cuáles son las tierras baldías de la Nación. En el 2012 el Incoder actualizó una base de los baldíos repartidos hasta el 2012, que estima en 23431557 hectáreas y en 619937 predios.

- Persisten las consecuencias del desplazamiento forzado de más de tres millones de personas, despojos directos de tierras de más de 6,5 millones de hectáreas y una apropiación ilegal de cuatro millones de hectáreas de baldíos.

- Concentración de la tierra. Existe una propiedad y tenencia marcadamente desigual. El INDH 2011 estimó un índice Gini de concentración de propiedad de la tierra de 0,87 .

El anterior recorrido permite establecer cómo, a pesar de la multiplicidad normativa que ha tenido Colombia en el transcurso de su historia, no ha existido una política pública consolidada en materia de tierras que permita el acceso y la formalización de tierra al campesino. Las diferentes normas han tratado de atender las problemáticas y luchas sociales de manera aislada, y no han contado con el interés político necesario para cumplir sus objetivos.

En conclusión, la falta de implementación de las diversas normas en materia de formalización y acceso a la tierra ha permitido que los elementos iniciales que dieron origen a los conflictos rurales en Colombia semantuvieran a lo largo de la historia. Sin embargo, durante las últimas décadas la titulación de baldíos ha sido uno de los instrumentos que más ha contribuido al acceso y la formalización de la tierra por parte de las familias campesinas.

\section{A. Análisis comparativo de la Ley 160 de 1994 y lo consagrado en el Acuerdo Final para la Terminación del Conflicto, en relación con la titulación de baldíos en Colombia}

Después de 11 meses de la firma del nuevo Acuerdo Final para la Terminación del Conflicto y la Construcción de una Paz Estable y Duradera, suscrito por las partes el 24 de noviembre del 2016 en Bogotá, se ha generado por parte del Estado colombiano una serie de ajuste normativos tendientes a dar cumplimiento a lo pactado con las Fuerzas Armadas Revolucionarias de Colombia (FARC), en los seis puntos principales del Acuerdo.

El punto número uno denominado "Hacia un Nuevo Campo Colombiano: Reforma Rural Integral” desarrolla una serie de propuestas que, en particular con respecto a la formalización de la propiedad, no han visto la luz en materia legislativa. Entre muchas circunstancias priman aquellas relacionadas con los intereses que prevalecen cuando el debate se centra en el acceso a la tierra. A fin de fortalecer los mecanismos para el acceso a la tierra y la formalización de la propiedad, el Acuerdo Final para la Terminación del Conflicto estableció que el Gobierno conformará un grupo de tres expertos, quienes en un periodo de tres meses realizarán las recomendaciones normativas y de política pública que impulsen la regularización de los derechos de la propiedad y faciliten el acceso a la tierra. De esta forma, solo se ha expedido el Decreto Ley 902 del 29 de mayo de 2017, por el cual se adoptan medidas para facilitar la implementación de la "Reforma Rural Integral" contemplada en el Acuerdo Final en materia de tierras, en específico en el procedimiento para el acceso, la formalización y el fondo de tierras.

En el desarrollo del presente capitulo es necesario, una vez abordados los principales aspectos de la Ley 160 de 1994 y sus decretos reglamentarios en materia de titulación de baldíos, identificar aquellos elementos fundamentales que se presentaron, de manera inicial, en el "Acuerdo General para la Terminación del Conflicto y la Construcción de una Paz Estable y Duradera" - suscrito el 26 de agosto de 2012 en La Habana Cuba-, y, posteriormente, en el nuevo "Acuerdo Final para la Terminación del Conflicto y la Construcción de una Paz Estable y Duradera".

\section{B. La Ley 160 de 1994 y la titulación de baldíos}

La Ley 160 de 1994, por medio de la cual se crea el Sistema Nacional de Reforma Agraria y Desarrollo Rural Campesino, ha sido en los últimos 20 años el derrotero normativo en materia de titulación de baldíos. En materia de baldíos se ha reglamentado por diferentes decretos, el primero de los cuales es el Decreto 2664 de 1994, modificado por el Decreto 982 de 1996. Finalmente, estos Decretos se han compilado en el Decreto 1071 del 26 de mayo de 2015, por medio del cual se expide el Decreto Único Reglamentario del Sector Administrativo Agropecuario, Pesquero y de Desarrollo Rural. Es importante recalcar que entre el intermedio de la normatividad relacionada estuvo temporalmente vigente la Ley 1152 de 2007 (Estatuto de Desarrollo Rural), declarada inexequible por la Corte Constitucional. 


\section{La Ley 160 de $1994^{60}$}

La Ley 160 de 1994 reglamentó, en su capítulo XII, la titulación de baldíos, la cual se ha mantenido vigente por más de 20 años en nuestro país. Esta ley se ha sometido a grandes debates originados en los compromisos suscritos en el Acuerdo de Paz.

La realización del análisis comparativo propuesto en el presente capitulo requirió establecer los principales conceptos objeto de comparación, para luego analizarlos en relación con la normatividad surgida del Acuerdo de Paz. Cabe aclarar que parte de los elementos identificados han sido confirmados y desarrollados por decretos reglamentarios, de los cuales se realiza una presentación posterior.

\section{Forma de adquisición (art. 65)}

La propiedad de los terrenos baldíos adjudicables solo puede adquirirse mediante título traslaticio de dominio otorgado por el Estado a través del Instituto Colombiano de la Reforma Agraria, o por las entidades públicas en las que delegue esta facultad, la cual se podrá realizar mediante solicitud previa de parte interesada o de oficio.

No podrá hacerse adjudicación de baldíos sino por ocupación previa, en tierras con aptitud agropecuaria que se estén explotando conforme a las normas sobre protección y utilización racional de los recursos naturales renovables.

\section{Sujetos de adjudicación}

De manera inicial, la norma señala tres calidades: personas naturales, empresas comunitarias y cooperativas campesinas. Posteriormente, en el artículo 68, incorpora como sujetos de adjudicación a las entidades de derecho público para la construcción de obras de infraestructura destinadas a la instalación o dotación de servicios públicos, o cuyas actividades hayan sido declaradas por la ley como de utilidad pública e interés social. De igual forma, incorpora a las fundaciones y asociaciones sin ánimo de lucro que presten un servicio público, o tengan funciones de beneficio social por autorización de la ley.

\section{3. Áreas adjudicables (art. 66)}

A partir de la vigencia de la Ley y como regla general, las tierras baldías se titularán en unidades agrícolas

60 Cf. Ley 160 de 1994, supra, nota 35. familiares, cuyo concepto fue definido en el capítulo Ix de la misma Ley. El Incora señaló de manera posterior para cada caso, región o municipio las extensiones máximas y mínimas adjudicables de las empresas básicas de producción y declarará, en caso de exceso del área permitida, que hay indebida ocupación de las tierras de la Nación.

En el texto inicial la Ley 160 de 1994 señalaba que el Incora cobrará el valor del área que exceda el tamaño de la unidad agrícola familiar establecida para las tierras baldías en la región o municipio, mediante el procedimiento de avalúo señalado para la adquisición de tierras. De hecho, la norma previó que el Incora podría establecer tarifas para cobrarse a los adjudicatarios de terrenos baldíos por los servicios de titulación. Este concepto fue revaluado con la Ley 1728 de 2014, por la cual se dictan normas de distribución de terrenos baldíos a familias pobres del país con fines sociales y productivos y se dictan otras disposiciones, y en la cual desaparece la figura. Por medio de la misma norma se establece que, en caso de existir áreas que excedan el tamaño de la UAF, se les dará el carácter de baldío reservados, susceptibles de ser adjudicados a otros campesinos.

\section{Baldíos lnadjudicables (art. 67)}

No serán adjudicables los terrenos baldíos situados dentro de un radio de 5 kilómetros alrededor de las zonas en las que se adelanten explotaciones de recursos naturales no renovables, las aledañas a parques nacionales naturales y las seleccionadas por entidades públicas para adelantar planes viales u otros de igual significación cuya construcción pueda incrementar el precio de las tierras por factores distintos a su explotación económica.

\section{Requisitos para la adjudicación (art. 69)}

La persona que solicite la adjudicación de un baldío deberá demostrar que tiene bajo explotación económica las dos terceras partes de la superficie cuya adjudicación solicita, y que la explotación adelantada corresponde a la aptitud del suelo establecida por el Incora en la inspección ocular. En todo caso deberá acreditarse una ocupación y explotación previa no inferior a cinco años para tener derecho a la adjudicación. La ocupación anterior de persona distinta del peticionario no es transferible a terceros para los efectos contemplados en este inciso. 
No podrá ser adjudicatario de baldíos la persona natural o jurídica cuyo patrimonio neto sea superior a 1000 salarios mínimos mensuales legales, salvo lo previsto para las empresas especializadas del sector agropecuario. En el caso de las sociedades deberá tenerse en cuenta, además, la suma de los patrimonios netos de los socios cuando estos superen el patrimonio neto de la sociedad.

\section{Prohibiciones (art. 72)}

No se podrán efectuar titulaciones de terrenos baldíos en favor de personas naturales o jurídicas que sean propietarias o poseedoras, a cualquier título, de otros predios rurales en el territorio nacional. Serán absolutamente nulas las adjudicaciones que se efectúen con violación de esta prohibición.

Ninguna persona podrá adquirir la propiedad sobre terrenos inicialmente adjudicados como baldíos, si las extensiones exceden los límites máximos de la titulación establecidos para las unidades agrícolas familiares en el respectivo municipio o región. En su aplicación se tendrán en cuenta, además, las adjudicaciones de terrenos baldíos efectuadas a sociedades de las que los interesados formen parte, lo mismo que las que figuren en cabeza de su cónyuge, compañero permanente e hijos menores que no hayan obtenido habilitación de edad.

Quien siendo adjudicatario de tierras baldías las hubiere enajenado, no podrá obtener una nueva adjudicación antes de transcurridos 15 años desde la fecha de la titulación anterior.

Los terrenos baldíos adjudicados no podrán fraccionarse en extensión inferior a la señalada por el Incora como Unidad Agrícola Familiar para la respectiva zona o municipio.

Las prohibiciones y limitaciones señaladas en los incisos anteriores deberán consignarse en los títulos de adjudicación que se expidan.

Dentro de los cinco años siguientes a la adjudicación de una Unidad Agrícola Familiar sobre baldíos, esta solo podrá ser gravada con hipoteca para garantizar las obligaciones derivadas de créditos agropecuarios otorgados por entidades financieras.

\section{Recursos}

La acción de nulidad contra las resoluciones de adjudicación de baldíos podrá intentarse por el Incora, por los procuradores agrarios o cualquier persona ante el correspondiente tribunal administrativo, dentro de los dos años siguientes a su ejecutoria o desde su publicación en el Diario Oficial, según el caso. Sin perjuicio de lo anterior, la norma señaló que el Incora podría revocar directamente, en cualquier tiempo, las resoluciones de adjudicación de tierras baldías proferidas con violación a lo establecido en las normas legales o reglamentarias vigentes sobre baldíos. En este caso no se exigirá el consentimiento expreso y escrito del respectivo titular. En lo demás, el procedimiento de revocación se surtirá con arreglo a las prescripciones del Código de lo Contencioso Administrativo.

\section{Reservas}

Llama la atención que la Ley 160 de 1994 le permitía al Incora constituir sobre los terrenos baldíos reservas en favor de entidades de derecho público para la ejecución de proyectos de alto interés nacional, tales como los relacionados con la explotación de los recursos minerales u otros de igual significación, para el establecimiento de servicios públicos o el desarrollo de actividades que hubieren sido declaradas por la ley como de utilidad pública e interés social, y las que tengan por objeto prevenir asentamientos en zonas aledañas o adyacentes a las zonas donde se adelanten exploraciones o explotaciones petroleras o mineras, por razones de orden público o de salvaguardia de los intereses de la economía nacional en este último caso. En igual sentido, el Instituto, con la aprobación del Gobierno, podría constituir reservas sobre tierras baldías, a fin de establecer en ellas un régimen especial de ocupación y de aprovechamiento.

Se debe tener en cuenta la figura de la reserva, ya que finalmente se constituye en una de las fuentes que alimenta un fondo de tierras.

\section{Decretos reglamentarios en materia de titulación de baldíos}

El Titulo 10 del Decreto 1071 de $2015^{61}$ recopila los decretos reglamentarios de la Ley 160 de 1994, en materia de titulación de baldíos. A continuación se presentan elementos claves de la titulación de baldíos y su respectivo procedimiento, los cuales serán

61 Cf. Decreto 1071 de 2015 [Ministerio de Agricultura y Desarrollo Rural]. Por medio del cual se expide el Decreto Único Reglamentario del Sector Administrativo Agropecuario, Pesquero y de Desarrollo Rural. Mayo 20 de 2015. 
objeto de análisis comparativo en relación con la normatividad surgida producto del Acuerdo de paz.

\section{Competencia (art. 2.14.10.1.1)}

La norma señala que el Instituto Colombiano de Desarrollo Rural administra en nombre del Estado las tierras baldías de propiedad nacional, y en virtud de esa atribución puede adjudicarlas, celebrar contratos, constituir reservas y adelantar colonizaciones sobre ellas, conforme a la Ley 160 de 1994.También corresponde al Incoder adelantar los procedimientos, ejercer las acciones y adoptar las medidas en los casos de indebida ocupación o apropiación de tierras baldías, o por incumplimiento de las condiciones bajo las cuales fueron adjudicadas.

Para tales efectos, decretará la caducidad de los contratos que celebre, ordenará la reversión de los baldíos adjudicados al dominio de la Nación y revocará directamente las resoluciones de titulación de baldíos proferidas con violación a lo establecido en las normas constitucionales, legales y reglamentarias vigentes, sin perjuicio de demandar su nulidad, con arreglo a la ley.

\section{Modo de adquisición (art. 2.14.10.1.3)}

La propiedad de los terrenos baldíos adjudicables únicamente puede adquirirse mediante título traslaticio de dominio expedido por el Incoder. La ocupación de tierras baldías no constituye título ni modo para obtener el dominio; quienes las ocupen no tienen la calidad de poseedores, conforme al Código Civil, y frente a la adjudicación por el Instituto solo existe una mera expectativa.

\section{Sujetos de adjudicación}

Se presentan tres calidades: las personas naturales y jurídicas, las entidades de derecho público y las sociedades.

\subsection{Personas naturales y jurídicas}

Sólo podrán hacerse adjudicaciones de baldíos por ocupación previa en favor de personas naturales, empresas comunitarias, cooperativas campesinas, fundaciones y asociaciones sin ánimo de lucro que presten un servicio público, o tengan funciones de beneficio social, y las sociedades de cualquier índole que sean reconocidas por el Ministerio de
Agricultura y Desarrollo Rural (MADR) como empresas especializadas del sector agropecuario; también podrán adjudicarse terrenos baldíos en favor de entidades de derecho público para la construcción de obras de infraestructura destinadas a la instalación o dotación de servicios públicos, o cuyas actividades hayan sido declaradas por la ley como de utilidad pública e interés social.

\subsection{Sociedades}

Las sociedades de cualquier índole reconocidas por el MADR como empresas especializadas del sector agropecuario podrán solicitar la adjudicación de terrenos baldíos en las zonas de desarrollo empresarial, previa la celebración y el cumplimiento del contrato de explotación respectivo.

\section{Unidad agrícola familiar (art. 2.14.10.3.1)}

Las tierras baldías solo podrán adjudicarse hasta la extensión de una unidad agrícola familiar. Para tal efecto se señalarán en cada región o municipio las extensiones de la unidad agrícola familiar. El Incora, en los casos excepcionales que determine su Junta Directiva, cobrará el valor del área que exceda el tamaño de la Unidad Agrícola Familiar establecida para las tierras baldías en la respectiva región o municipio, mediante el avalúo señalado para la adquisición de tierras.

\section{Requisitos para la adjudicación (art. 2.14.10.4.19)}

Las personas naturales, las empresas comunitarias y las cooperativas campesinas que soliciten la adjudicación de un terreno baldío deberán demostrar que tienen bajo explotación económica las dos terceras partes de la superficie cuya adjudicación solicitan, y que la explotación adelantada corresponde a la aptitud del suelo establecida por el Incoder en la inspección ocular. Los peticionarios deberán acreditar una ocupación y explotación previa no inferior a cinco años y que su patrimonio neto no sea superior a 1000 salarios mínimos mensuales legales. Cuando se trate de empresas comunitarias y de cooperativas campesinas, para efectos de la prohibición anterior deberá tenerse en cuenta, además, la suma de los patrimonios netos de los socios cuando estos superen el patrimonio neto de la sociedad. El tiempo de ocupación de persona distinta del peticionario no es transferible a terceros en ningún caso. 


\section{Baldíos inadjudicables (art. 2.14.10.4.2.)}

No serán adjudicables los terrenos baldíos que se hallen en las siguientes circunstancias:

- Los aledaños a los parques nacionales naturales.

- Los que hubieren sido seleccionados por entidades públicas para adelantar planes viales u otros de igual significación para el desarrollo económico y social del país o de la región.

- Los que tuvieren la calidad de inadjudicables, conforme a la ley, o que constituyan reserva territorial del Estado.

- No podrán hacerse adjudicaciones de baldíos donde estén establecidas comunidades indígenas o que constituyan su hábitat, sino únicamente y con destino a la constitución de resguardos indígenas. En igual sentido los terrenos en zonas de reserva forestal, los cuales solo podrán destinarse a la constitución de resguardos indígenas.

\section{Prohibiciones (art. 2.14.10.4.3)}

Además de las previstas en la ley y en otras disposiciones vigentes, no podrán adjudicarse tierras baldías:

- A quienes habiendo sido adjudicatarios de terrenos baldíos, los hubieren enajenado antes de cumplirse quince (15) años desde la fecha de la titulación anterior.

- A las personas naturales y jurídicas que sean propietarias, o poseedoras a cualquier título, de otros predios rurales en el territorio nacional.

- A quienes no reúnan los requisitos o se hallen afectados por las limitaciones señaladas en la Ley 160 de 1994.

\section{E. El "Acuerdo General para la Terminación del Conflicto y la Construcción de una Paz Estable y Duradera"}

El Acuerdo General fue producto de los encuentros exploratorios que sostuvieron los delegados del Gobierno de la República de Colombia y de las FARC, entre el 23 de febrero y el 26 de agosto del 2012 en La Habana, Cuba, en el cual se establece la agenda que se desarrollará con el fin de alcanzar un acuerdo final. El primer punto de la agenda se denominó "Política de desarrollo Agrario Integral", en el cual se reconoce que este es determinante para impulsar la integración de las regiones y el desarrollo social y económico equitativo del país. A su vez, el numeral uno enuncia los concepto de acceso y uso de la tierra, tierras improductivas, formalización de la propiedad, frontera agrícola y protección de zonas de reserva, en los cuales se enmarca la titulación de baldíos.

Establecer en la agenda los asuntos del desarrollo agrario integral y del acceso a la tierra con mecanismos como, por ejemplo, la titulación de baldíos, reconocen la importancia que le dieron las partes a esta problemática, sobre los cuales se centró parte de la lucha armada en un largo periodo de tiempo. Es importante recordar que, como una de las reglas de funcionamiento de la agenda desarrollada, las partes acordaron que las conversaciones se darían bajo el principio de que nada está acordado hasta que todo esté acordado, lo cual le brindó un concepto de integralidad a los puntos desarrollados.

\section{F. El Nuevo Acuerdo Final para la Terminación del Conflicto y la Construcción de una Paz Estable y Duradera}

El Nuevo Acuerdo Final para la Terminación del Conflicto y la Construcción de una paz Estable y Duradera se suscribió el 24 de noviembre del 2016 en Bogotá. Fue producto de la manifestación de diversos sectores del pueblo colombiano que a través de un plebiscito, adelantado el 2 de octubre del 2016, expresaron su descontento a lo establecido en el primer acuerdo suscrito el 24 de agosto del 2016 en La Habana, Cuba. De acuerdo con lo establecido en el Acuerdo General, el primer punto del nuevo Acuerdo desarrolla la "Reforma Rural Integral", reconociendo en él causas históricas del conflicto como, por ejemplo, la propiedad sobre la tierra, así como su concentración.

\section{Hacia un nuevo campo colombiano: "Reforma Rural Integral"}

El punto uno del Acuerdo pretende contribuir a la transformación estructural del campo mediante la creación de condiciones para el bienestar de la población rural y al señalar medidas encaminadas a promover el uso adecuado de la tierra y estimular la formalización, la restitución y la distribución equitativa de esta. En la implementación de la "Reforma Rural Integral”, el acuerdo estableció los siguientes principios: 
- Transformación estructural.

- Desarrollo integral del campo.

- Igualdad y enfoque de género.

- Bienestar y buen vivir.

- Priorización.

- Integralidad.

- Restablecimiento.

- Regularización de la propiedad.

- Derecho a la alimentación.

- Participación.

- Beneficio, impacto y medición.

- Desarrollo sostenible.

- Presencia del Estado.

- Democratización del acceso y uso adecuado de la tierra.

El principio de regularización de la propiedad se relaciona con la lucha contra la ilegalidad en la posesión y propiedad de la tierra, y las garantías de los derechos de los poseedores y dueños; el principio de democratización del acceso y uso adecuado de la tierra se enfoca en los mecanismos que permitan a un mayor número de campesinos sin tierra o con tierra insuficiente acceder a ella. Cabe señalar que la titulación de baldíos es uno de los procedimientos que se relaciona directamente con estos dos principios.

2. Mecanismos para el acceso a la tierra y la formalización de la propiedad

\subsection{Fondo de Tierras para la Reforma Integral}

El Fondo promueve la democratización del acceso a la tierra en beneficio de campesinos y comunidades rurales sin tierra o con tierra insuficiente. El acuerdo señala que este será permanente y dispondrá de tres millones de hectáreas durante sus primeros 12 años de creación, las cuales provendrán, principalmente, de:

- Tierras provenientes de la extinción de dominio.

- Tierras recuperadas a favor de la Nación (baldíos indebidamente ocupados).

- Tierras provenientes de la sustracción de reservas forestales.

- Tierras adquiridas o expropiadas por motivos de interés social o de utilidad pública.

- Tierras donadas.

De igual forma, utilizará mecanismos como, por ejemplo, el subsidio integral para la compra de tierras y los créditos especiales para la compra de tierras.

\subsection{Formalización masiva de la pequeña y mediana propiedad rural}

Este mecanismo busca garantizar los derechos de las personas que sean legitimas dueñas y poseedoras de la tierra. El Acuerdo establece la formalización de siete millones de hectáreas, para lo cual expresa que el Gobierno deberá adelantar las reformas normativas y operativas pertinentes priorizando zonas de atención y garantizando la gratuidad de la formalización en la adjudicación de baldíos.

Finalmente, en relación con el acceso a la tierra y a estimular la formalización, la restitución y su distribución equitativa, se deben resaltar dos aspectos novedosos que señaló el Acuerdo. El primero, que los predios baldíos formalizados serán inalienables e inembargables por un periodo de siete años, con lo cual se busca evitar la concentración de la propiedad y proteger el uso de la función social de la propiedad rural; el segundo, compromete la creación de una nueva jurisdicción agraria con cobertura y capacidad en el territorio.

\section{Fondo de Tierras para la Reforma Rural Integral}

El Decreto Ley 902 de 2017 establece la creación del Fondo de Tierras para la Reforma Rural Integral como un fondo especial que operara como una cuenta, sin personería jurídica, cuya administración será ejercida por la Agencia Nacional de Tierras. Los recursos del Fondo provendrán de las siguientes fuentes:

- Los recursos del presupuesto que le aporte la Nación.

- Los recursos destinados al adelantamiento de los programas de asignación de subsidio integral de reforma agraria de los que trata la Ley 160 de 1994 o el que haga sus veces.

- El producto de los empréstitos que la Nación contrate con destino al Fondo.

- Los dineros y créditos en los que figure como acreedora la Agencia Nacional de Tierras, producto del pago del precio de bienes inmuebles que enajene.

- Las sumas que reciba la Agencia Nacional de Tierras como contraprestación de los servicios que preste.

- Las donaciones o auxilios que le hagan personas naturales o jurídicas, nacionales o extranjeras, así como entidades internacionales. 
- Los recursos que los municipios, los distritos, los departamentos y otras entidades acuerden destinar para cofinanciar programas de la Agencia Nacional de Tierras.

- Los rendimientos financieros provenientes de la administración de sus recursos que no sean parte del Presupuesto General de la Nación.

- Los recursos que conforman el Fondo de Desarrollo Rural, Económico e Inversión (FDREI), conforme a lo establecido por la Ley 1776 de 2016 para la adquisición de tierras por fuera de las Zidres.

- Los recursos provenientes de organismos internacionales o de cooperación internacional.

- Predios rurales obtenidos en compensación por el desarrollo de proyectos que hayan implicado la entrega de tierras baldías o fiscales patrimoniales de la ANT.

- Los predios rurales que se reciba del ICBF por sucesiones intestadas, así como los bienes vacantes que la Ley 75 de 1968 le atribuyó al Incora.

- Los que sean transferidos por parte de entidades de derecho público.

- Los predios rurales que ingresen al Fondo en virtud de la aplicación de procedimientos administrativos o judiciales, como, por ejemplo, la extinción de dominio por incumplimiento de la función social o ecológica de la propiedad, la expropiación o la recuperación de baldíos indebidamente ocupados, entre otros.

- Las tierras provenientes de la sustracción, el fortalecimiento y la habilitación para la adjudicación de las zonas de reserva forestal de la Ley 2 de 1959, y de conformidad con lo dispuesto en la normatividad vigente incluyendo la Ley 99 de 1993 y el Código de Recursos Naturales Renovables.

- Las tierras baldías con vocación agraria a partir de la actualización del inventario de áreas de manejo especial que se hará en el marco del plan de zonificación ambiental al que se refiere el Acuerdo Final, con sujeción a acciones de planeación predial, de producción sostenible y conservación, y de conformidad con lo dispuesto en la normatividad vigente.

- Los bienes baldíos que tengan la condición de adjudicables.

- Los bienes inmuebles que se adquieran para adelantar programas de acceso a tierras.

- Los predios rurales adjudicables de propiedad de la Agencia Nacional de Tierras.

- Los bienes inmuebles rurales que sean trasferidos por la entidad administradora, provenientes de la declaración de extinción del dominio, por estar vinculados directa o indirectamente a la ejecución de los delitos de narcotráfico y conexos, o que provengan de ellos.

\section{Conclusiones}

En relación con el primero objetivo, tendente a identificar y analizar los antecedentes de carácter normativo, tanto históricos como vigentes que han regulado el tema de la titulación de bienes baldíos de carácter rural en Colombia, se tiene que, si bien en materia de reforma agraria en Colombia se ha intentado pasar de un concepto simple basado en la propiedad de la tierra a uno integral que aborde de manera totalitaria la problemática rural, en la práctica no se ha logrado desarrollar, a pesar de los esfuerzos normativos en la materia. Colombia no evidencia una evolución clara de los modelos jurídicos aplicados en los procesos de titulación de baldíos y la normatividad agraria se ha mantenido en un círculo vicioso de avances y retrocesos, es decir, de forma periódica a través de diferentes normas se han incorporado definiciones, procedimientos, requisitos y restricciones que, en la mayoría de los casos, han sido modificados y sustraídos por normas siguientes y retomados de nuevo en ciclos posteriores.

La titulación de baldíos en Colombia, como instrumento de acceso y formalización, a partir de su propósito y reglamentación, más que de sus resultados, permite observar tres grandes momentos. La Ley 200 de 1936, la cual buscó la recomposición de la tenencia de la tierra a partir de los terrenos baldíos, a través de la legalización de las posesiones de hecho y la titulación a arrendatarios, aparceros y colonos; la Ley 135 de 1961, la cual contenía un alto contenido redistributivo; y la Ley 160 de 1994, por la cual introdujo el subsidio para la compra directa de tierras, de manera que dinamizó el mercado de tierras, más allá de la titulación de baldíos.

La Corte Constitucional Colombiana ha mantenido una posición garantista en relación con el acceso a tierras por parte de los sujetos de titulación de baldíos, la cual ha conllevado a que en varias ocasiones tome posiciones que incluso han llevado a declarar inexequibles normas que contrarían los principios constitucionales. A pesar de lo anterior, sus múltiples esfuerzos no han sido suficientes para estimular la implementación de la titulación de baldíos de una forma coordinada y articulada. 
La reforma rural integral producto del Nuevo Acuerdo Final para la Terminación del Conflicto y la Construcción de una Paz Estable y Duradera retoma como punto central el acceso y la formalización de la tierra, elemento que se ha sido eje fundamental de la normatividad en materia agraria desarrollada en Colombia desde finales del siglo xix. En razón a la naturaleza del país y la ausencia del cierre de la frontera agrícola, la titulación de baldíos ha sido y será un instrumento útil que ha permitido la formalización y el acceso a la tierra.

Los cambios establecidos en el Decreto Ley 902 de 2017 no sustituyen los principios fundamentales establecidos en la Ley 160 de 1994 en relación con la titulación de baldíos, norma que con sus decretos reglamentarios continuos es aún el derrotero en la materia. Las modificaciones del Decreto Ley 902 de 2017, las cuales pretenden adecuar la normatividad para la implementación de la "Reforma Rural Integral" contemplada en el Acuerdo Final en materia de tierras, no representan los ajustes necesarios para el cumplimiento de los objetivos, entre los que se encuentran la formalización de siete millones de hectáreas y el fondo de tierras con un capital a distribuir de tres millones de hectáreas. El contenido normativo del Decreto Ley 902 de 2017 perpetúa el círculo vicioso de avance y retrocesos en el que se han mantenido los diseños de políticas agrarias desde sus inicios en Colombia, producto de los intereses contrapuestos en relación con la propiedad de la tierra. Como elemento innovador el Decreto Ley 902 de 2017 incorpora de diversos procedimientos en un procedimiento único, el cual para el caso de titulación de baldíos se agrupa en asignación y reconocimiento de derechos de propiedad sobre predios administrados.

\section{REFERENCIAS}

Absalón Machado. EnsAyos PARA LA HISTORIA DE LA POLÍTICA DE TIERRAS EN COLOMBIA. Universidad Nacional de Colombia. (2009).

Absalón Machado. Reforma agraria. Una ilusión que terminó en fracaso. Revista Credencial Historia 119. 1999.

Absalón Machado y Ruth Suárez. Coord. El MerCado DE TIERRAS EN COLOMbia: ¿UNA ALTERNATIVA VIABLE? Centro de Estudios Ganaderos y Agrícolas (CEGA), Instituto Interamericano de Cooperación para la Agricultura (IICA). (1999).
Albert Berry. (2002). ¿Colombia encontró por fin una reforma agraria que funcione? Revista de ECONOMÍA INSTITUCIONAL 4(6). Pág. 24-70.

Álvaro Balcázar, Nelson López, Martha Lucía Orozco y Margarita Vega, supra, nota 3.

Álvaro López Toro. Migración y cambio social en Antioquia durante el siglo XIX. Demografía y ECONomía 2(3). 1968. Págs. 351-403.

Ángela Barriga. ¿ACUMULACión IRREgUlAR DE TIERRAS ADJUdicadas COMO BALDíos? DUdAS ANTE LA EXPEDiCión DE LA LEY ZidRes Y SU POSIBLE DISONANCIA CON LO ACoRdado en La Habana. (2017).

Angélica María Franco e Ignacio de los Ríos. Reforma agraria en Colombia: evolución histórica del concepto. Hacia un enfoque integral actual. CUADERNOS DE DESARROLLO RURAL 8(67). 2011. Págs. 93-119.

Cristóbal Kay. Reforma agraria, industrialización y desarrollo: ¿Por qué Asia Oriental superó a América Latina? Debate Agrario 34. Págs. 45-94. 2002.

Álvaro Balcázar, Nelson López, Martha Lucía Orozco y Margarita Vega. Colombia: ALCANCeS y lecciones DE SU EXPERIENCIA EN REForma Agraria. Santiago de Chile: Naciones Unidas-Red de Desarrollo Agropecuario, Unidad de Desarrollo Agrícola, División de Desarrollo Productivo y Empresarial. (2001).

Banco Mundial. Colombia: una política de tierras en TRANSICIÓN. Documento CEDE, 2004-29, Facultad de Economía, Universidad de los Andes. (2004).

Bersarión Gómez Hernández. La tenencia de la tierra y la reforma agraria en Colombia. Verba IURIs. Enero-junio 2011.

Catherine LeGrand. Colonización y PROTESTA CAMPESina en Colombia 1850-1950. Universidad Nacional de Colombia. (1988).

César Vargas, Gonzalo Téllez, Alexander Cubillos, Jaime Pulido, Paola Gómez y Lady Garzón. Análisis de los beneficiarios de la Política Pública de Reforma Agraria en el marco del desarrollo rural en Colombia (19942010). Pampa 13. 2016. Págs. 31-53.

Corte Constitucional Colombiana. Sentencia C-595/95. (MP Carlos Gaviria Díaz: diciembre 7 de 1995).

Darío Fajardo M. La tierra y el poder político; la reforma agraria y la reforma rural en Colombia. BolETín FAO. Rома. 2002.

Darío Fajardo. Colombia: reforma agraria en la solución de conflictos armados. América Latina, Hoy 23. (1999). Págs. 45-59. 
Decreto 1071 de 2015 [Ministerio de Agricultura y Desarrollo Rural]. Por medio del cual se expide el Decreto Único Reglamentario del Sector Administrativo Agropecuario, Pesquero y de Desarrollo Rural. Mayo 20 de 2015.

Decreto 2363 de 2015. Por la cual se crea la Agencia Nacional de Tierras ANT, se fija su objetivo y estructura. Diciembre 7 de 2015.

Elsy Marulanda A. APLICACIÓn y eFECTOS DE LA LEY 200 DE 1936 EN LA REGIÓN DE SuMAPAZ. Universidad Nacional de Colombia (Sede Bogotá). Facultad de Ciencias Humanas. Departamento de Historia.

Francisco Gutiérrez Sanín. Desigualdad extrema: una PREOCUPACIÓN POLÍTICA. LAS POLÍTICAS RURALES EN COLOMBIA EN EL PERIODO 2002 -2009. (2012).

Gabriel Rosas Rosas. (2005). Reforma agraria, no más dilaciones. Economía Colombiana 309. Págs. 33-44.

Gonzalo Sánchez y Ricardo Peñaranda. Pasado y PREsente de la violencia en Colombia. Cerec. (1986).

Héctor Castañeda. Los baldíos en Colombia. Grupo Editorial Leyer. (1998).

Joaquín Vanín Tello. Derecho Agrario Teoría General. Tомоs 1 y 11. Editorial Universidad Externado de Colombia. (1986).

Josefina Amezquita de Almeida. Régimen legal DE BALdíos en Colombia. Editorial Temis. (1961).

Juan José Botero. ADJUdiCACión, EXPLOTACióN Y COMERCIALIZACIÓN DE BALDÍOS Y BOSQUES NACIONALES. Evolución HistóRICO LEgISLATIVA, 1830-1930. Banco de la República. (1994).

Incora COMPILACIÓN DE NORMAS SOBRE ADJUDICACIONES BALDIOS, RESERVAS INDÍGENAS, PARCELACIONES. Publicaciones del Incora. (1970).

José M. Martínez Aparicio. RÉGIMEN DE BALDíos. Ediciones 2000.
Marcos Palacios. ¿De Quién es la tierra? Propiedad, POLITIZACIÓN Y PROTESTA CAMPESINA EN LA DÉCADA DE 1930. Fondo de Cultura Económica, Universidad de los Andes. (2011).

Luis Augusto Cangrejo Cobos. XI Congreso nacional en derecho procesal, Instituto Colombiano de Derecho Procesal, la jurisdicción agraria. REvisTAS ICDP 10(10-11). 1991.

Ley 160 de 1994. Por la cual se crea el Sistema Nacional de Reforma Agraria y Desarrollo Rural Campesino, se establece un subsidio para la adquisición de tierras, se reforma el Instituto Colombiano de la Reforma Agraria. Agosto 3 de 1994. Do 41479.

Margarita Gáfaro, Ana María Ibáñez y David Zarruk. EQUIDAD Y EFICIENCIA RURAL EN COLOMBIA: UNA DISCUSIÓN DE POLÍTICAS PARA EL ACCESO A LA TIERRA. (2012). Documentos CEDE 010318. Universidad de los Andes-CEDE.

Ministerio de Agricultura y Desarrollo Rural. CARTILla DE POLítica AGROPECUARIA 2010-2014. Ministerio de Agricultura y Desarrollo Rural. (2012).

Olga Marina García Norato. Tendencias historiográficas sobre el problema agrario en Colombia siglo XX. REVISTA DE INVESTIGACIONES UNAD.

Parsons. La COLONIZACIÓN ANTIOQUEÑa EN EL OCCIDENTE de Colombia. Banco de la República. (1961).

Programa de las Naciones Unidas para el Desarrollo-PNUD. Colombia Rural: razones para la esperanza. Informe Nacional de Desarrollo Humano. Programa de las Naciones Unidas para el Desarrollo. (2011).

Salomón Kalmanovitz y Enrique López. LA AGRIcultura colombiana en el siglo Xx. Banco de la República. (2006). 